\title{
Enriched-Baicalein Attenuates Allergy in Cells and Mice
}

\author{
Mi-Young Yun, ${ }^{1}$ Ju-Im Jung, ${ }^{2}$ Sung-Min Park, ${ }^{3}$ and Hwa-Jung Choi $\mathbb{D}^{1}$ \\ ${ }^{1}$ Department of Beauty Science, Kwangju Women's University, 165 Sanjeong-dong, Gwangsan-gu, Gwangju 506-713, \\ Republic of Korea \\ ${ }^{2}$ Department of Beauty Science, Gwangju University, 277 Hyodeok-ro, Nam-Gu, Gwangju, Republic of Korea \\ ${ }^{3}$ CossedBioPharm, 68 Osongsaengmyeong 2-ro, Osong-eup, Heungdeok-gu, Cheongju-si, Chungcheongbuk-do, \\ Republic of Korea
}

Correspondence should be addressed to Hwa-Jung Choi; rerived@naver.com

Received 28 January 2020; Revised 17 April 2020; Accepted 1 May 2020; Published 29 June 2020

Guest Editor: Reggiani Vilela Gonçalves

Copyright $\odot 2020 \mathrm{Mi}$-Young Yun et al. This is an open access article distributed under the Creative Commons Attribution License, which permits unrestricted use, distribution, and reproduction in any medium, provided the original work is properly cited.

Enriched-baicalein (baicalein) from baicalin was prepared by fermentation of an SB extract with mycelium of Laetiporus sulphureus. To investigate the pharmacologic effects of baicalein, its antiallergic effect was measured in vitro and in vivo. Allergy was induced by intraperitoneal injection of ovalbumin (OVA) into Balb/c mice. As a result, baicalein showed antiallergic effects by inhibiting the release of $\beta$-hexosaminidase from immunoglobulin E- (IgE-) stimulated rat basophilic leukemia (RBL-2H3) mast cells without cytotoxicity after the methodology. After four weeks, the decrease of OVA-specific IgE level, decrease of histamine and tryptase level in serum, and then the decrease of the levels of $\mathrm{T}$ helper type $2\left(\mathrm{~T}_{\mathrm{h}} 2\right)$ cellderived cytokines interleukin- (IL-) 4 and IL-13 in the splenocyte were observed. In a histological analysis for lung, baicalein excellently reduced eosinophil infiltration with the inhibition of characteristic lesions and inflammation including OVAinduced necrosis, numbers of inflammatory cells, and pulmonary edema. Therefore, these results showed that baicalein had excellent efficacy in the antiallergic activity.

\section{Introduction}

Scutellaria baicalensis Georgi (SB), Chinese name, "Huangqin," has been routinely used in the treatment of bronchitis, hepatitis, allergy, atopy, inflammation, and arteriosclerosis and has been listed in the Pharmacopoeia of China [1]. Early reports also suggested that SB possessed anti-inflammatory, antioxidant, and antiallergic effects [2].

Many flavonoids are better antioxidants than other antioxidant nutrients such as Vitamins C, E, and l-carotene on a mole for mole basis [3]. In radix S. baicalensis Georgi, flavonoids with $O$-di-hydroxyl group or $O$-three-hydroxyl group or in ring $\mathrm{A}$, such as baicalin and baicalein, could be good free-radical scavengers [4]. Baicalin which is a glycoside and active component of SB has low bioavailability and rate of low absorption in the body [5].

Conversion of baicalin into baicalein as an aglycon form can increase efficacy and rate of absorption by fermentation [6]. Bioconversion produces an effective component from a precursor by substrate specificity of the enzyme [7]. This process boosts the pharmacological effect and rate of absorption in the body by converting glycoside present in natural material to aglycon, which is the active form [8]. It is reported that aglycon forms of baicalein in SB, monoglycoside of geniposide in Gardenia jasminoides, and glycyrrhizin in Glycyrrhiza uralensis are derived from the deglycosylation of baicalin, geniposide, and glycyrrhetinic acid, respectively [9]. Those aglycons are absorbed in the body more effectively and show a stronger pharmacologic effect [10].

An allergic reaction is characterized by the excessive activation of mast cells and basophils, leading to the release of various mediators such as histamine and an array of cytokines [11]. Plasma concentrations of immunoglobulin E (IgE) can be markedly elevated in some individuals with allergic diseases [12]. Antigen-dependent activation of tissue mast cells that have specific IgE bound to their surface is the central event in acute allergic reactions [11]. Production of 
antigen-specific IgE requires that such antigens are taken up by dendritic cells, B cells, or other antigen-presenting cells, which, in the presence of interleukin-4 (IL-4) or IL-13 provided early in the process by one or more cell types, present the processed antigens to cognate naive $\mathrm{T}$ cells that, then, acquire a $\mathrm{T}$ helper type $2\left(\mathrm{~T}_{\mathrm{h}} 2\right)$ cell phenotype [13].

Our previous report showed that enriched-baicalein from baicalin by fermentation of SB extract with mycelium of Laetiporus sulphureus shows an antiwrinkle effect in ultraviolet B- (UVB-) induced mice model and in vitro [14]. This study is aimed to identify the antiallergic effects of the baicalein by bioconversion in vitro and in vivo. The effects of the baicalein on the release of $\beta$-hexosaminidase were conducted in IgE-stimulated rat basophilic leukemia (RBL$2 \mathrm{H} 3$ ) mast cells. The Balb/c mice induced allergy by intraperitoneal injection of ovalbumin (OVA). The OVA-specific $\operatorname{IgE}$ in the serum of mice was measured using the Mouse OVA-IgE ELISA kit. The histamine and tryptase level in serum of mice were measured with the fluorometric method and the B12 assay, respectively. $\mathrm{T}_{\mathrm{h}} 2$ cells-derived cytokines IL-4 and IL-13 in splenocytes were measured by using an ELISA kit. Histologic analyses of lung samples from mice were performed by $\mathrm{H} \& \mathrm{E}$ staining.

\section{Materials and Methods}

2.1. Materials. All reagents were purchased from SigmaAldrich (St. Louis, MO, USA). SB was purchased from the Jecheon oriental medical herb shopping mall (Jechon city, Chungcheongbuk-do, South Korea). L. sulphureus var. miniatus (called L. sulphureus CS0218) was originally isolated from a mountainous district in Jeonnam province, South Korea, and identified by Dr. SM Park. These were obtained from the culture collection of CoSeedBiopharm company (patent pending, Deposit no: KFCC 11494P). Baicalein was produced by SB fermented with mycelium of L. sulphureus for 6 days in our laboratory as previously [14]. Dexamethasone and ovalbumin were purchased from Sigma-Aldrich (Sigma-Aldrich Co., St. Louis, MO., USA). Dulbecco's modified eagle's medium (DMEM), fetal bovine serum (FBS), penicillin-streptomycin (PS), and phosphatebuffered saline (PBS) were purchased from WelGENE (Daegu, Korea). Trypsin-EDTA (Gibco, BRL., Rockville, $\mathrm{MD})$, 2,2-diphenyl-1-picrylhydrazyl (DPPH), nitro blue tetrazolium (NBT), xanthin, xanthine oxidase, dimethyl sulfoxide (DMSO), EtOH (Daejung, Gyeonggi-do, Korea), L. sulphureus var. miniatus (KFCC 11494P, Korea), IL-4, IL13, IgE ELISA kit (Biosource, USA), anti-CD3 (serotec., UK.), homogenizer (OMNI, Co., USA), plate shaker (Labline, Co., USA), flow cytometer (Molecular Devices, Co., USA), and an ELISA reader (Molecular Devices, Co., USA) were used.

2.2. Animal and Application. To identify the antiallergic effect of enriched-baicalein in ovalbumin-induced mice, the method used was the method reported in our previous paper [15]. Briefly, twenty-five Specific-Pathogen-Free (SPF) Balb/ c male mice (14-22 g each and 5 weeks old) were purchased from Charles River Japan (Kanagawa, Japan). Mice were housed at $21 \pm 2$ with $55 \pm 15 \%$ humidity of a 12 h light-dark cycle (light on 7 AM, 7 PM) in SPF conditions. All experimental protocols were approved by the Institutional Animal Care and Use Committee (IACUC) of Daejeon University, South Korea (DJUARB2013-028). All procedures were executed according to the Guide for the Care and Use of Laboratory Animals. The effects were made to minimize the number of animals used and their discomfort. After preliminary breeding for 1 week, the mice were divided into five groups randomly. Normal, OVA-control, dexamethasone, baicalein, and SB were acclimated for 1 week before use. Balb/c males (6 weeks old) were used and ovalbumin was injected intraperitoneally for $0,7,14,21$, and 28 days to $\mathrm{Balb} / \mathrm{c}(n=5)$. The baicalein containing $100 \mathrm{mg}$ of baicalein/ $\mathrm{kg}$ body weight per day was dissolved in $0.4 \%$ polyethylene glycol in $0.5 \% \mathrm{EtOH}$ and was applied topically on a daily basis for 4 weeks.

2.3. Cytotoxicity Assay. Rat basophilic leukemia (RBL-2H3) mast cells were obtained from the American Type Culture Collection (ATCC, Manassas, VA) cultured at $37^{\circ} \mathrm{C}$ in a $5 \%$ $\mathrm{CO}_{2}$ humidified incubator. RBL-2H3 cells were incubated in an EMEM medium containing $10 \%$ FBS and $1 \%$ antibioticantimycotic at $37^{\circ} \mathrm{C}$. The cytotoxic effects of the SB extract and baicalein were measured by 3-(4,5-dimethylthiazol-2yl)-2,5-diphenyltetrazolium bromide (MTT) assay on RBL$2 \mathrm{H} 3$ mast cells by the treatment of $50,100,200$, and $500 \mu \mathrm{g} \cdot \mathrm{mL}^{-1}$ [16]. Dimethyl sulfoxide $(0.01 \%)$ was used for all no-drug control samples.

2.4. Release of $\beta$-Hexosaminidase from IgE-Stimulated RBL$2 \mathrm{H} 3$ Mast Cells. The antiallergy assay was based mostly on the methods described by Zhu et al. and Yun et al. with slight modification $[2,17]$. RBL-2H3 cells were seeded on a 96-well plate $\left(2 \times 10^{5}\right.$ cells.well $\left.^{-1}\right)$. After incubation for $24 \mathrm{hrs}$, the medium was supplemented with $0.5 \mu \mathrm{g} \cdot \mathrm{mL}^{-1}$ anti-DNP (dinitrophenol) mouse IgE. The microplate was incubated for $24 \mathrm{hrs}$ and replaced with Tyrode's buffer of $100 \mu \mathrm{L}$. The compound dissolved in DMSO $(<0.5 \%$ per well) was added and incubated again for $30 \mathrm{~min}$ and then replaced with $100 \mu \mathrm{L}$ of Tyrode's buffer containing $50 \mu \mathrm{g} / \mathrm{mL}$ DNP-bovine serum albumin (BSA) (Invitrogen, Carlsbad, CA, USA). After incubation of $1 \mathrm{~h}$, the $50 \mu \mathrm{L}$ of the supernatant was collected from the microplate and mixed with a substrate solution ( $p$-nitrophenyl- $N$-acetyl- $\beta$-glucosaminide, $2 \mathrm{mM}$ ) of $50 \mu \mathrm{L}$ in a new 96-well microplate. The microplate mixed was incubated at room temperature for $3 \mathrm{hrs}$ using a shaker. Finally, a stop solution of $100 \mu \mathrm{L}$ was added, and the absorbance of the plate was read at $405 \mathrm{~nm}$.

2.5. OVA-Specific IgE Level in Serum. The tested animals were anesthetized for euthanasia with the reagents of isoflurane and sodium pentobarbital. Isoflurane was administered by inhalation at an overdose of $4 \%$ with oxygen as a carrier gas for $5 \mathrm{~min}$ in a sealed chamber under a pressure of 6 psi by using inhalation anesthesia apparatus (IWOO 
Scientific Corporation, Seoul, Korea) at room temperature to induce euthanasia according to the IACUC Guidelines for the Euthanasia of Korea. The blood from mice was centrifuged at $4000 \mathrm{~g}$ for $10 \mathrm{~min}$. The serum was collected and stored at $-20^{\circ} \mathrm{C}$ until use.

OVA-specific IgE antibody was measured using the Mouse OVA-IgE ELISA kit (Shibayagi Co., Shibukawa, Japan). According to the manufacturer's protocol, $1 \mathrm{U}$ of the anti-OVA IgE is defined as $1.3 \mathrm{ng}$ of the antibody. The absorption of $450 \mathrm{~nm}$ (subwavelength, $620 \mathrm{~nm}$ ) for OVAspecific IgE was measured by a microplate reader (Spectrafluor, Tecan, Salzburg, Austria).

2.6. Histamine and Tryptase Assay in Serum. The heparinized blood was kept at $4^{\circ} \mathrm{C}$ (a maximum of 24-48 h) after its extraction. After the separation of the plasma by centrifuging, plasma histamine was analyzed by the fluorometric method following the technique modified by Siraganian [18] with an AutoAnalyzer 3 (Bran Luebbe, SEAL Analytical Inc, Mequon, WI, USA). Serum tryptase levels were measured with the B12 assay [19], using ImmunoCAP Tryptase reagents and the Phadia 250 analysis device (Phadia AB, Uppsala, Sweden).

2.7. Measurement of Cytokines Level. Animals were killed by decapitation one day after the measurement of OVA-specific IgE level, histamine, and tryptase levels. To measure the cytokine level, OVA/alum was conducted by intraperitoneal injection. Then, spleen cells were collected from each mouse after 4 weeks. Cytokine measurements in the spleen cells $\left(2 \times 10^{6} \mathrm{~mL}^{-1}\right)$ were cultured for $48 \mathrm{hrs}$ in a culture dish (Corning Inc., USA.), which had been coated with CD3 mAb of $0.5 \mu \mathrm{g} \cdot \mathrm{mL}^{-1}$ for $12 \mathrm{hrs}$. Then, IL- 4 and IL-13 were measured by using an ELISA kit. After washing the plate twice, the Avidin-HRP-conjugated antibody of $100 \mu \mathrm{L}$ was treated and washed. TMB solution was treated for $30 \mathrm{~min}$ in the dark. After stopping the reaction with a stop solution of $50 \mu \mathrm{L}$, the absorbance was measured at $450 \mathrm{~nm}$ by using the ELISA reader.

2.8. Histological Analysis for the Lungs. Lungs of mice were inflated with PBS containing heparin and tied off. After removing of lungs from the mice, they were placed in $10 \%$ formalin for 10 days and the affected percentage of lungs were assessed macroscopically. The lungs were embedded into paraffin, sectioned at $5 \mu \mathrm{m}$ thickness, and stained with hematoxylin and eosin as described before [20]. Histological analysis was performed under a light microscope (Leica DM 1000, Germany) at high magnification (250x). All macroscopic and microscopic lesions were analyzed independently by an unbiased respiratory expert blinded from the study.

2.9. Statistical Analysis. All measurements were made in triplicate and all values are represented as mean \pm SD using Microsoft Excel 2010. The results were subjected to an analysis of variance (ANOVA) using the Tukey test to analyze differences; $p<0.05, p<0.01$, and $p<0.001$ were considered significant.

\section{Results}

3.1. Cytotoxicity of Baicalein. To search the noncytotoxicity concentration of the SB extracts and baicalein, we evaluated the effect of the SB extracts and baicalein on the viability of RBL-2H3 mast cells. After $24 \mathrm{hrs}$, the cytotoxicity was conducted in culture using the MTT tetrazolium reduction test. As a result, both baicalein and SB extracts did not show cytotoxicity up to $500 \mu \mathrm{g} \cdot \mathrm{mL}^{-1}$, and at the highest concentration of $500 \mu \mathrm{g} / \mathrm{mL}$, baicalein showed lower cytotoxicity than that of SB extract (Figure 1(a)).

\subsection{Effect of Baicalein on the Release of $\beta$-Hexosaminidase In} Vitro. We investigated the antiallergic effects by checking the release of $\beta$-hexosaminidase from IgE-stimulated RBL$2 \mathrm{H} 3$ mast cells. Baicalein exhibited significant inhibitory effects at $12.5 \mu \mathrm{g} \cdot \mathrm{mL}^{-1}$ and $25 \mu \mathrm{g} \cdot \mathrm{mL}^{-1}$ as shown in Figure 1(b). The inhibitory rate of baicalein was higher than that of SB. SB showed an inhibitory rate of $54.7 \%$ against $\beta$-hexosaminidase release at $25 \mu \mathrm{g} \cdot \mathrm{mL}^{-1}$. However, SB and baicalein did not show an inhibitory effect against $\beta$-hexosaminidase release at $1 \mu \mathrm{g} \cdot \mathrm{mL}^{-1}$.

3.3. OVA-Specific IgE. Six-week-old Balb/c males were used and ovalbumin was injected intraperitoneally for $0,7,14,21$, and 28 days to Balb/c $(n=5)$. The OVA-specific IgE in the serum of mice was measured using the Mouse OVA-IgE ELISA kit. The study showed that the formation of OVAspecific IgE was suppressed (Figure 2). Control groups produced significant IgE as compared to the normal group, and the positive control group, dexamethasone, was to suppress the generation of IgE significantly at four weeks and two weeks (Figure 2). SB extracts showed significant inhibition at 4 weeks and baicalein showed a significant reduction in 2 and 4 weeks, respectively (Figure 2). These results demonstrated that the efficacy of baicalein is more greatly increased than that of the SB extract.

\subsection{Effect of Baicalein on Histamine and Tryptase in Serum.} Serum histamine levels were significantly higher in the control group compared with the normal group $(p<0.001)$ and were significantly smaller in the dexamethasone $\left(2 \mathrm{mg} \cdot \mathrm{kg}^{-1}\right), \quad$ SB extract $\left(100 \mathrm{mg} \cdot \mathrm{kg}^{-1}\right)$, and baicalein $\left(100 \mathrm{mg} \cdot \mathrm{kg}^{-1}\right)$ groups compared with the control group (all $p<0.05$; Figure 3(a)). This finding indicated that treatment of baicalein significantly improved the serum histamine contents in mice with significant difference from the control groups.

Serum tryptase levels were significantly increased in the control group $(p<0.001)$. Administration of dexamethasone $\left(2 \mathrm{mg} \cdot \mathrm{kg}^{-1}\right)$ was significantly lower in the control group $(p<0.05$; Figure $3(\mathrm{~b}))$. The baicalein $\left(100 \mathrm{mg} \cdot \mathrm{kg}^{-1}\right)$ groups significantly decreased the tryptase level of mice serum $(p<0.05)$, which was lower than that of SB groups. 


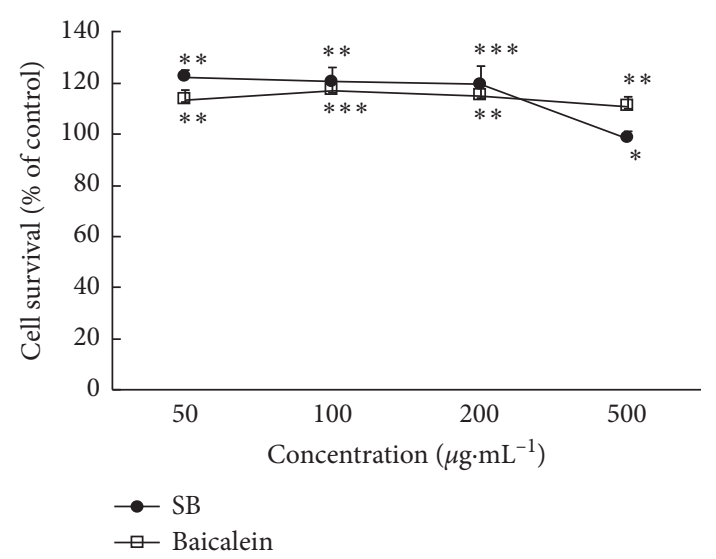

(a)

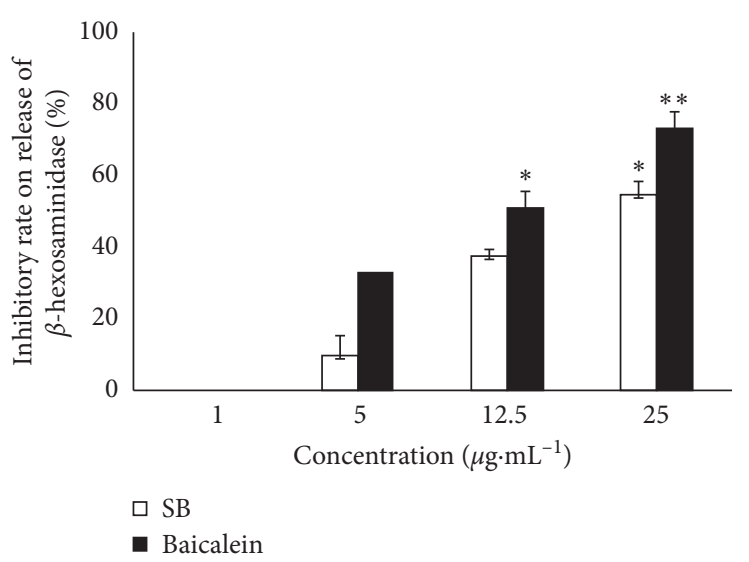

(b)

Figure 1: Cytotoxicity of baicalein against RBL-2H3 mast cells (a) and inhibitory rate on the release of $\beta$-hexosaminidase by baicalein treatment in RBL-2H3 mast cells. (b) Cytotoxicity of SB extract and baicalein $\left(50,100,200\right.$, and $500 \mu \mathrm{g} \cdot \mathrm{mL}^{-1}$, respectively) was measured by 3-(4,5-dimethylthiazol-2-yl)-2,5-diphenyltetrazolium bromide (MTT) assay on RBL-2H3 mast cells after $24 \mathrm{~h}$. The cytotoxicity was expressed as a percentage. The inhibitory rates on the release of $\beta$-hexosaminidase by baicalein treatment were conducted in IgE-stimulated

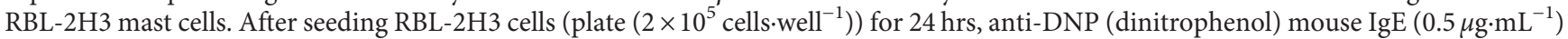
was supplemented. After $24 \mathrm{~h}$, Tyrode's buffer $(100 \mu \mathrm{L})$ was added, the plate was incubated for 30 min, and Tyrode's buffer $(100 \mu \mathrm{L})$ containing $50 \mu \mathrm{g} / \mathrm{mL}$ DNP-bovine serum albumin (BSA) was replaced. After incubation of $1 \mathrm{~h}$, the $50 \mu \mathrm{L}$ of the supernatant was collected and mixed with substrate solution (p-nitrophenyl-N-acetyl- $\beta$-glucosaminide, $2 \mathrm{mM}$ ) of $50 \mu \mathrm{L}$. After 3 hrs, a stop solution of $100 \mu \mathrm{L}$ was added, and the absorbance of the plate was read at $405 \mathrm{~nm}$. Dimethyl sulfoxide $(0.01 \%)$ was used for all no-drug control samples. All measurements were made in triplicate and all values are represented as mean $\pm \mathrm{SD}$. SB, Scutellaria baicalensis Georgi extract. ${ }^{*} p<0.05$, ${ }^{* *} p<0.01$, and ${ }^{* * *} p<0.001$.

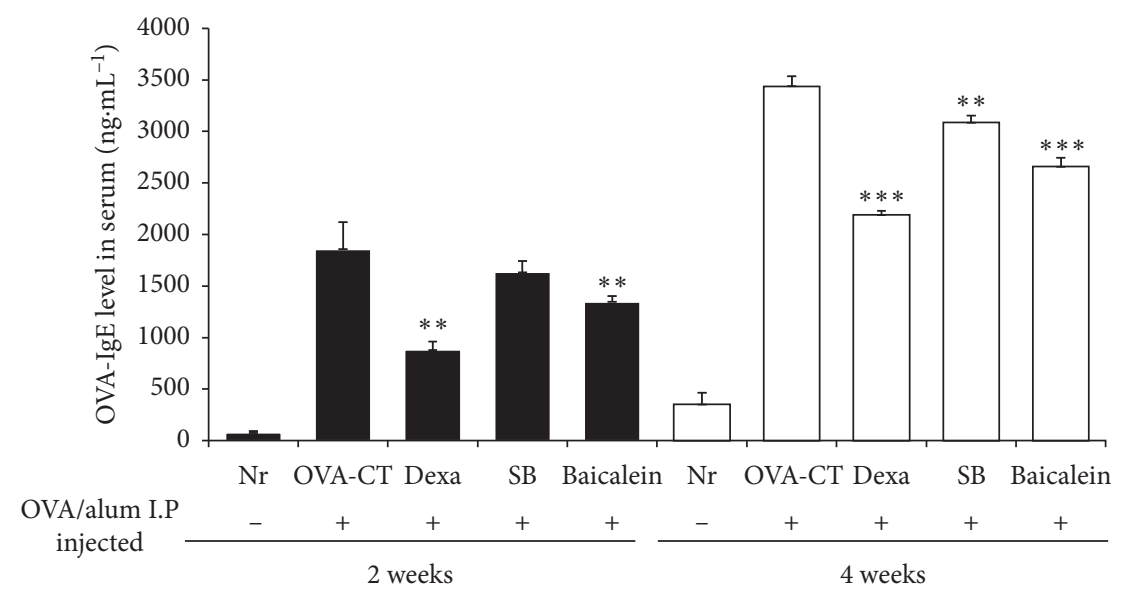

FIGURE 2: Effect of baicalein on the serum OVA-specific IgE levels in ovalbumin applied Balb/c. Six-week-old Balb/c males were used and OVA was injected intraperitoneally for $0,7,14,21$, and 28 days to Balb/c $(n=5)$. The baicalein, containing $100 \mathrm{mg}$ of baicalein $\cdot \mathrm{kg}^{-1} \mathrm{body}$ weight per day dissolved in $0.4 \%$ polyethylene glycol in $0.5 \% \mathrm{EtOH}$, was applied topically on a daily basis for four weeks. OVA-specific IgE cytokine levels of the serum in mice were determined. OVA-specific IgE antibody was measured using the Mouse OVA-IgE ELISA kit. The absorption of $450 \mathrm{~nm}$ (subwavelength, $620 \mathrm{~nm}$ ) for OVA-specific IgE was measured by a microplate reader. All measurements were made in triplicate and all values are represented as mean $\pm \mathrm{SD}$. Nr, normal; OVA-CT, control treated with only ovalbumin; Dexa., dexamethasone. $\mathrm{SB}$, Scutellaria baicalensis Georgi extract. ${ }^{*} p<0.05,{ }^{* *} p<0.01$, and ${ }^{* * *} p<0.001$ showed a significant difference from OVA-CT.

\section{5. $T_{h} 2$ Cells-Derived Cytokines $I L-4$ and $I L-13$.} OVA/alum was to be an intraperitoneal injection. Spleen cells were prepared from each mouse after four weeks in the positive control group (dexamethasone), SB extract group, and the baicalein group. Five $\times 10^{5}$ cells/well was divided on a 96-well plate onto which $\mathrm{CD} 3 \mathrm{mAb}$ was coated at a concentration of $0.5 \mu \mathrm{g} \cdot \mathrm{mL}^{-1}$ before $12 \mathrm{hrs}$. The study has shown that as the production of IL- 4 and IL-13 was measured and analyzed with ELISA in the culture supernatant after $48 \mathrm{hrs}, \mathrm{T}_{\mathrm{h}} 2$ cells-derived cytokines IL- 4 and IL13 showed a significant reduction effect compared to the control group (Figures 4(a) and 4(b)).

3.6. Histological Analysis for the Lungs. Histologic analyses were performed at lung samples of mice after four weeks. 


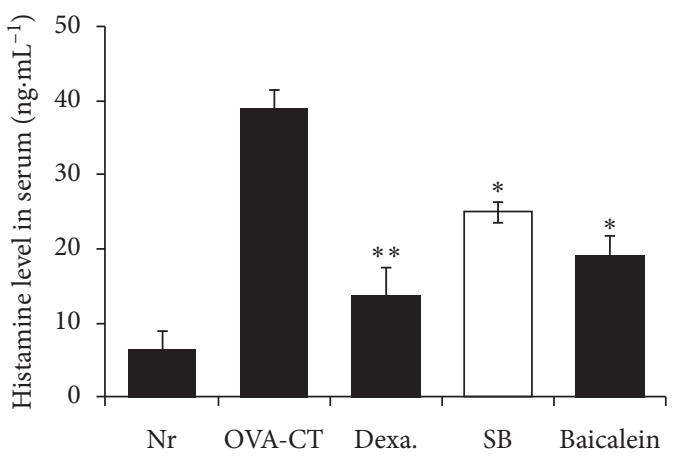

(a)

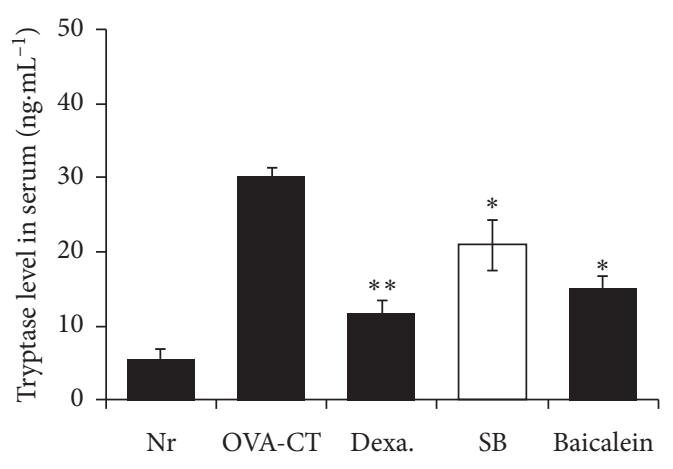

(b)

FiguRE 3: Effect of baicalein on the histamine (a) and tryptase levels (b) in ovalbumin applied Balb/c mice. Six-week-old Balb/c males were used and ovalbumin was injected intraperitoneally for $0,7,14,21$, and 28 days to Balb/c $(n=5)$. The baicalein, containing $100 \mathrm{mg}$ of baicalein $\cdot \mathrm{kg}^{-1}$ body weight per day dissolved in $0.4 \%$ polyethylene glycol in $0.5 \% \mathrm{EtOH}$, was applied topically on a daily basis for four weeks. Histamine and tryptase levels in the serum of mice were measured. The plasma histamine was analyzed by the fluorometric method with an AutoAnalyzer 3. Serum tryptase levels were measured with the B12 assay using ImmunoCAP Tryptase reagents and the Phadia 250 analysis device. All measurements were made in triplicate and all values are represented as mean $\pm \mathrm{SD}$. Nr, normal; OVA-CT, control treated with only ovalbumin; Dexa., dexamethasone; SB, Scutellaria baicalensis Georgi extract. ${ }^{*} p<0.05$ and ${ }^{* *} p<0.01$ showed a significant difference from OVA-CT.

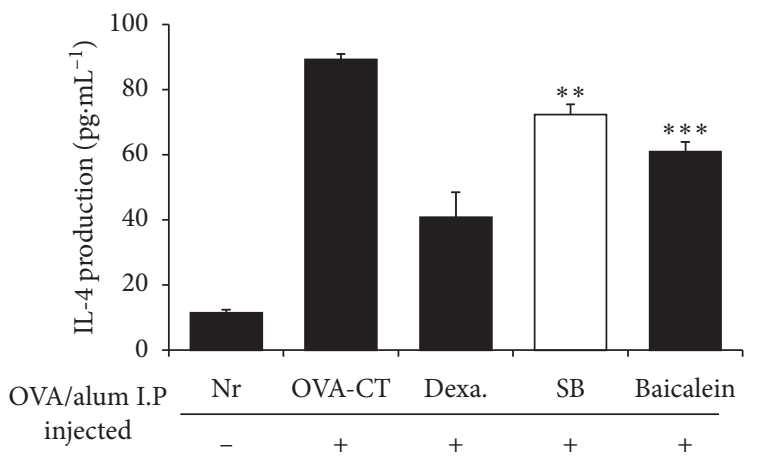

(a)

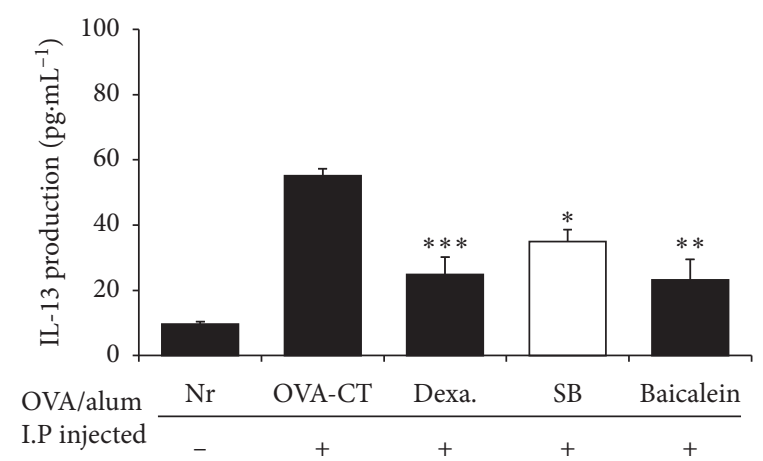

(b)

FIGURE 4: Effect of baicalein on IL-4 (a) and IL-13 (b) production in the culture supernatant of CD3 stimulated splenocytes. Balb/c males (6 weeks old) were used and ovalbumin was injected intraperitoneally for $0,7,14,21$, and 28 days to Balb/c $(n=5)$. The baicalein, containing $100 \mathrm{mg}$ of baicalein $/ \mathrm{kg}$ body weight per day dissolved in $0.4 \%$ polyethylene glycol in $0.5 \% \mathrm{EtOH}$, was applied topically on a daily basis for four weeks. Cytokine measurements in the spleen cells $\left(2 \times 10^{6} \mathrm{~mL}^{-1}\right)$ were cultured for $48 \mathrm{hrs}$ in a culture dish, which had been coated with CD3 mAb. Then, IL-4 and IL-13 levels were measured. The production of IL-4 and IL-13 was measured with ELISA in the culture supernatant. All measurements were made in triplicate and all values are represented as mean $\pm \mathrm{SD}$. Nr, normal; OVA-CT, control treated with only ovalbumin; Dexa., dexamethasone; SB, Scutellaria baicalensis Georgi extract. ${ }^{*} p<0.05,{ }^{* *} p<0.01$, and ${ }^{* * *} p<0.001$ showed a significant difference from OVA-CT.

Figure 5 shows representative H\&E staining of lungs in the normal, OVA-CT, dexamethasone $\left(2 \mathrm{mg} \cdot \mathrm{kg}^{-1}\right), \mathrm{SB}$ extract $\left(100 \mathrm{mg} \cdot \mathrm{kg}^{-1}\right)$, and baicalein $\left(100 \mathrm{mg} \cdot \mathrm{kg}^{-1}\right)$ groups. In the figure, eosinophils appear as small black dots, as indicated by arrows. In the normal group, eosinophils were rarely observed (Figure 5(a)). However, in the OVA-CT group, eosinophils densely surrounded bronchioles and showed characteristic lesions and inflammation including increased necrosis and numbers of inflammatory cells and pulmonary edema (Figure 5(b)). Treatment with dexamethasone $\left(2 \mathrm{mg} \cdot \mathrm{kg}^{-1}\right.$ ) and $\mathrm{SB}$ extracts (OV00 mg. kg ${ }^{-1}$ ) moderately reduced this eosinophil infiltration (Figures 5(c) and 5(d), respectively). Treatment with baicalein $\left(100 \mathrm{mg} \cdot \mathrm{kg}^{-1}\right)$ excellently reduced this eosinophil infiltration with inhibition of characteristic lesions and inflammation (Figure 5(e)).

\section{Discussion}

Allergy and inflammation can evident as hyperresponsiveness to allergenic substances in various target organs of the human body [21]. Allergic reactions are triggered when allergens crosslink conducted IgE bound to the high-affinity receptor (FC"RI) on mast cells [11]. The mast cells then degranulate and release various molecules such as chemokines, histamine, prostaglandins, and other cytokines [22]. In a previous study, Rhodomyrtus tomentosa (Aiton) Hassk. fruits inhibit mast cell 


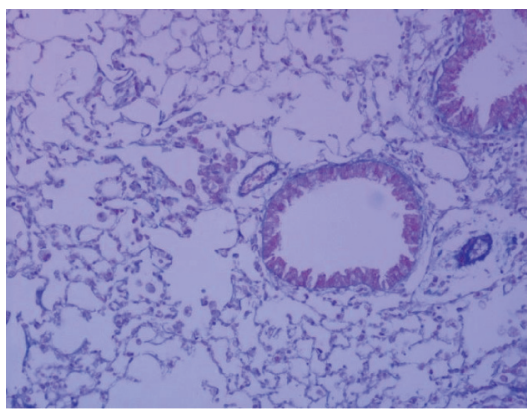

(a)

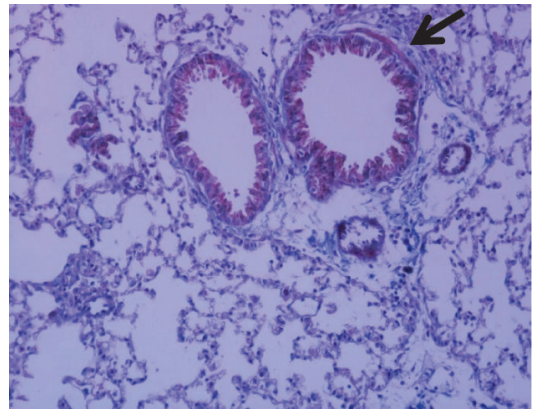

(d)

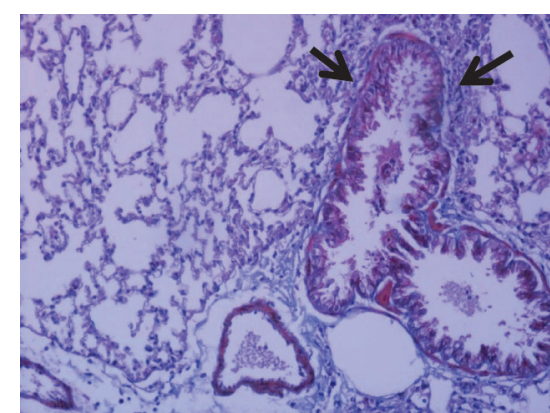

(b)

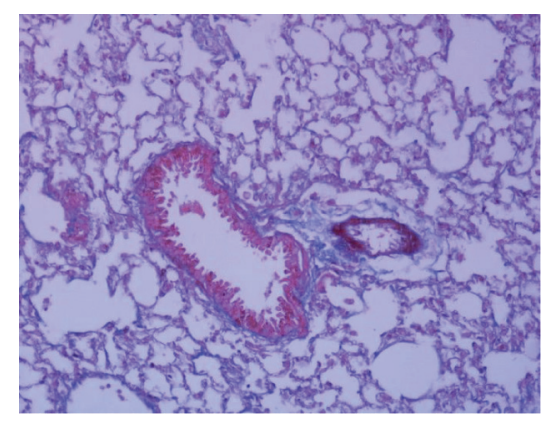

(c)

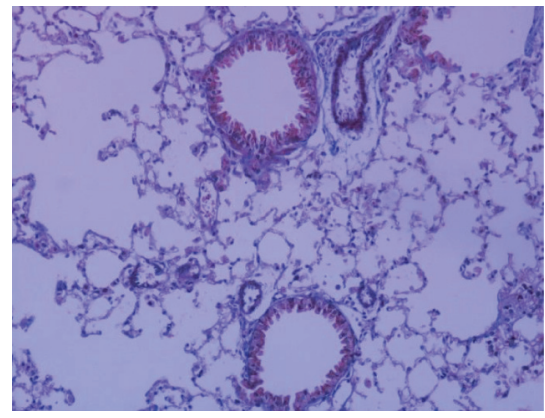

(e)

FIGURE 5: Histological analysis by baicalein administration in ovalbumin applied Balb/c mice. Balb/c males (6 weeks old) were used and ovalbumin was injected intraperitoneally for $0,7,14,21$, and 28 days to Balb/c $(n=5)$. The baicalein, containing $100 \mathrm{mg}$ of baicalein $/ \mathrm{kg}$ body weight per day dissolved in $0.4 \%$ polyethylene glycol in $0.5 \% \mathrm{EtOH}$, was applied topically on a daily basis. After four weeks, the lung was stained with hematoxylin and eosin and histological analysis was carried out under a light microscope at 250x magnification. (a) Normal group; (b) ovalbumin control group; (c) dexamethasone group; (d) Scutellaria baicalensis Georgi extract group; (e) baicalein group.

degranulation via decreasing $\beta$-hexosaminidase release [23]. In our study, baicalein showed similar results inhibiting the release of $\beta$-hexosaminidase from IgE-stimulated RBL-2H3 mast cell showing significant inhibitory activity at $12.5 \mu \mathrm{g} \cdot \mathrm{mL}^{-1}$ and $25 \mu \mathrm{g} \cdot \mathrm{mL}^{-1}$.

The IgE level in the serum of atopic dermatitis was known to be immunological indicators [24]. When the antigen-stimulated the human body, IgE antibodies are generated and secreted by the interaction between the $\mathrm{T}_{\mathrm{h}} 2$ cell and $\mathrm{B}$ cell. Sensitization occurred when IgE was secreted by binding to the IgE receptor on the mast cell surface [25]. Also, the antigen reenters the human body and binds to IgE on the surface of mast cells activated, and then after degranulation was induced, there were chemical mediators and various inflammatory cytokines and granular materials in a cell [26]. It is said that allergic symptoms appeared due to the chemical mediators of some allergies secreted from that and it was confirmed by animal experiments that a mixture of $R$. radix, peony, and wild rice in natural products decreased the numerical value of $\operatorname{IgE}$ [27]. In a paper, an aqueous extract of peanut skin and its main constituent procyanidin A1 suppress serum IgE and IgG1 levels in mice immunized with ovalbumin [28]. In our study, quercetin 3glucoside-7-rhamnoside from Hippophae rhamnosides L. fruits showed an antiallergic effect in ovalbumin-induced allergic mice [15]. In this article, baicalein also showed a significant reduction of OVA-specific IgE level in serum at 4 weeks and 2 weeks.

The cytoplasm of mast cells is rich in endocrine granules that will synthesize and release various bioactive media and factors in response to stimuli, including histamine, 5-hydroxytryptamine (5-HT), tryptase, prostaglandins, and cytokines [27]. Mast cell-derived active substances, such as histamine, 5-HT, tryptase, prostaglandins, cytokines, and leukotriene, which are most likely to act on the enteric nervous system, can potentially activate visceral afferent nerves, resulting in gastrointestinal discomfort and hypersensitivity $[29,30]$. In a related article, berberine suppressed mast cell activation and allergic responses inhibiting the release of $\beta$-hexosaminidase ( $\beta$-HEX), histamine, IL- 4 , and TNF- $\alpha$ in RBL-2H3 cells [31]. In another paper, the allergic response was attenuated by Bupleurum chinense extracts via inhibiting the mast cell accumulation in the nasal mucosa and serum histamine release [32]. As the above two studies, baicalein significantly improved the serum histamine contents in mice with a significant difference from the control groups and significantly decreased the tryptase level of mice serum, which was lower than that of the SB groups.

IL-13 and IL- 4 derived from $\mathrm{T}_{\mathrm{h}} 2$ cells that were activated early in the allergic reaction stimulated B-lymphocytes and converted this into plasma cells that produced IgE [33]. IL-4 was a growth factor for B cells and played a role in stimulating the switch of the Ig heavy chain of immunoglobulin into IgE of the same type [34]. By suppressing the expression of IL-4, T cells were blocked to differentiate into $\mathrm{T}_{\mathrm{h}} 2$ cells [35]. Under normal conditions, the expression of IL-4 was increased when atopic dermatitis occurred [36]. Therefore, if the balance of both cytokines was formed, increasing the 
expression of IFN- $\gamma$ after lowering the expression of IL-4 and IL-13, it was commonly found to be able to cure atopic dermatitis [37]. Siraitia grosvenorii residual extract attenuated OVA-induced lung inflammation by downregulating IL-4, IL-5, IL-13, IL-17, and MUC5AC expression in mice [38]. Gallic acid inhibited nasal inflammation via the activation of $T_{h} 1$ and inhibition of $T_{h} 2$ and $T_{h} 17$ in a mouse model of allergic rhinitis [39]. In these results, the decrease of $\mathrm{T}_{\mathrm{h}} 2$ cell-derived cytokines IL- 4 and IL-13 in splenocyte after four weeks was shown. Those results were similar to the above reports.

\section{Conclusion}

In this study, the baicalein possesses an antiallergic effect showing the inhibition of the release of $\beta$-hexosaminidase from IgE-stimulated RBL-2H3 mast cells, the decrease of OVA-specific IgE level, the decrease of histamine and tryptase level in serum, and then the decrease of the levels of $\mathrm{T}_{\mathrm{h}} 2$ cell-derived cytokines IL- 4 and IL-13 in splenocytes. This study is limited in that it did not identify specific mechanisms of action by baicalein possessing the antiallergic effect. Therefore, further investigation of the mode of action of this baicalein will be continued in our future projects.

\section{Data Availability}

The data used to support the findings of this study are available from the corresponding author upon request.

\section{Conflicts of Interest}

The authors declare that there are no conflicts of interest.

\section{Acknowledgments}

This study was conducted by research funds from Gwangju University in 2020 .

\section{References}

[1] T. Kumagai, C. I. Müller, J. C. Desmond, Y. Imai, D. Heber, and H. P. Koeffler, "Scutellaria baicalensis, a herbal medicine: anti-proliferative and apoptotic activity against acute lymphocytic leukemia, lymphoma and myeloma cell lines," Leukemia Research, vol. 31, no. 4, pp. 523-530, 2007.

[2] M.-Y. Yun, J.-H. Yang, D.-K. Kim et al., "Therapeutic effects of baicalein on atopic dermatitis-like skin lesions of $\mathrm{NC} / \mathrm{Nga}$ mice induced by dermatophagoides pteronyssinus," International Immunopharmacology, vol. 10, no. 9, pp. 1142-1148, 2010.

[3] C. A. Rice-Evans, N. J. Miller, P. G. Bolwell, P. M. Bramley, and J. B. Pridham, "The relative antioxidant activities of plantderived polyphenolic flavonoids," Free Radical Research, vol. 22, no. 4, pp. 375-383, 1995.

[4] D. N. Olennikov, N. K. Chirikova, and L. M. Tankhaeva, "Phenolic compounds of Scutellaria baicalensis Georgi," Russian Journal of Bioorganic Chemistry, vol. 36, no. 7, pp. 816-824, 2010.

[5] C. Xu and G. E. Ji, "Bioconversion of flavones during fermentation in milk containing Scutellaria baicalensis extract by
Lactobacillus brevis," Journal of Microbiology and Biotechnology, vol. 23, no. 10, pp. 1422-1427, 2013.

[6] I. L. F. Nielsen, W. S. S. Chee, L. Poulsen et al., "Bioavailability is improved by enzymatic modification of the citrus flavonoid hesperidin in humans: a randomized, double-blind, crossover trial," The Journal of Nutrition, vol. 136, no. 2, pp. 404-408, 2006.

[7] E. Skoronski, M. Fernandes, M. Magalhães et al., "Substrate specificity and enzyme recycling using chitosan immobilized laccase," Molecules, vol. 19, no. 10, pp. 16794-16809, 2014.

[8] I. Marotti, A. Bonetti, B. Biavati, P. Catizone, and G. Dinelli, "Biotransformation of common bean (Phaseolus vulgaris L.) flavonoid glycosides by Bifidobacterium species from human intestinal origin," Journal of Agricultural and Food Chemistry, vol. 55, no. 10, pp. 3913-3919, 2007.

[9] T. Akao, K. Kawabata, E. Yanagisawa et al., "Balicalin, the predominant flavone glucuronide of Scutellariae Radix, is absorbed from the rat gastrointestinal tract as the aglycone and restored to its original form," Journal of Pharmacy and Pharmacology, vol. 52, no. 12, pp. 1563-1568, 2000.

[10] T. Akao, K. Kobashi, and M. Aburada, "Enzymic studies on the animal and intestinal bacterial metabolism of geniposide," Biological \& Pharmaceutical Bulletin, vol. 17, no. 12, pp. 1573-1576, 1994.

[11] S. J. Galli and M. Tsai, "IgE and mast cells in allergic disease," Nature Medicine, vol. 18, no. 5, pp. 693-704, 2012.

[12] H. J. Gould and B. J. Sutton, "IgE in allergy and asthma today," Nature Reviews Immunology, vol. 8, no. 3, pp. 205-217, 2008.

[13] R. S. Geha, H. H. Jabara, and S. R. Brodeur, "The regulation of immunoglobulin E class-switch recombination," Nature Reviews Immunology, vol. 3, no. 9, pp. 721-732, 2003.

[14] K. Y. Yun, E. Y. Wou, J. H. Lee, J. I. Jung, and H. J. Choi, "Bioconversion from Scutellaria baicalensis (baicalin) fermented with Leatiporus sulphureus into enriched-baicalein and anti-wrinkle effects," Pharmacognosy Magazine, vol. 14, no. 57, pp. S453-S457, 2018.

[15] H. J. Choi, "Quercetin 3-glucoside-7-rhamnoside from Hippophae rhamnosides L. fruits attenuate allergy in ovalbumininduced allergic mouse," Biomedical Journal of Scientific \& Technical Research, vol. 21, no. 2, pp. 15734-15740, 2019.

[16] T. Mosmann, "Rapid colorimetric assays for cellular growth and survival: application to proliferation and cytotoxicity assays," Journal Immunological Methods, vol. 65, no. 1-2, pp. 55-63, 1983.

[17] Q. Zhu, T. Nakagawa, A. Kishikawa, K. Ohnuki, and K. Shimizu, "In vitro bioactivities and phytochemical profile of various parts of the strawberry (fragaria $\times$ ananassa var. amaou)," Journal of Functional Foods, vol. 13, pp. 38-49, 2015.

[18] R. P. Siraganian, "An automated continuous-flow system for the extraction and fluorometric analysis of histamine," Analytical Biochemistry, vol. 57, no. 2, pp. 383-394, 1974.

[19] G. Granerus, B. Lonnqvist, J. Nystrand, and G. Roupe, "Serum tryptase measured with B12 and G5 antibody-based immunoassays in mastocytosis patients and its relation to histamine turnover," British Journal of Dermatology, vol. 139, no. 5, pp. 858-861, 1998.

[20] V. Ölschlaäger, S. Pleschka, T. Fisher et al., "Lung-specific expression of active raf kinase results in increased mortality of influenza A virus-infected mice," Oncogene, vol. 23, no. 39, pp. 6639-6646, 2004.

[21] T. Juckmeta, P. Thongdeeying, A. Itharat, T. Juckmeta, P. Thongdeeying, and A. Itharat, "Inhibitory effect on $\beta$-hexosaminidase release from RBL-2H3 cells of extracts and some pure constituents of benchalokawichian, a Thai herbal 
remedy, used for allergic disorders," Evidence-Based Complementary Alternative Medicine, vol. 2014, Article ID 828760 , 8 pages, 2014.

[22] M. Jutel and C. A. Akdis, "Immunological mechanisms of allergen-specific immunotherapy," Allergy, vol. 66, no. 6, pp. 725-732, 2011.

[23] T. S. Vo, Y. S. Kim, D. N. Ngo, and D. H. Ngo, "The role of Rhodomyrtus tomentosa (aiton) hassk. Fruits in downregulation of mast cells-mediated allergic responses," BioMed Research International, vol. 2019, Article ID 3505034, 7 pages, 2019.

[24] D. Y. M. Leung, M. Boguniewicz, M. D. Howell, I. Nomura, and Q. A. Hamid, "New insights into atopic dermatitis," Journal of Clinical Investigation, vol. 113, no. 5, pp. 651-657, 2004.

[25] N. Novak, T. Bieber, and D. Y. Leung, "Immune mechanisms leading to atopic dermatitis," Journal of Allergy and Clinical Immunology, vol. 112, no. 6, pp. S128-S139, 2003.

[26] E. Tahara, W. Wu, T. Satoh et al., "Psychosocial stress enhances IgE-mediated triphasic cutaneous reaction in mice: antagonism by Yokukan-san (a Kampo medicine) and diazepam," Allergology International, vol. 50, no. 3, pp. 211-221, 2001.

[27] M.-C. Kim, C.-H. Lee, and T.-H. Yook, "Effects of anti-inflammatory and Rehmanniae radix pharmacopuncture on atopic dermatitis in NC/Nga mice," Journal of Acupuncture and Meridian Studies, vol. 6, no. 2, pp. 98-109, 2013.

[28] F. Takano, T. Takata, A. Yoshihara, Y. Nakamura, Y. Arima, and T. Ohta, "Aqueous extract of peanut skin and its main constituent procyanidin A1 suppress serum IgE and IgG1 levels in mice-immunized with ovalbumin," Biological \& Pharmaceutical Bulletin, vol. 30, no. 5, pp. 922-927, 2007.

[29] D. Grundy, E. D. Al-Chaer, Q. Aziz et al., "Fundamentals of neurogastroenterology: basic science," Gastroenterology, vol. 130, no. 5, pp. 1391-1411, 2006.

[30] N. Vergnolle, N. W. Bunnett, K. A. Sharkey et al., "Proteinaseactivated receptor-2 and hyperalgesia: a novel pain pathway," Nature Medicine, vol. 7, no. 7, pp. 821-826, 2001.

[31] S. Fu, S. Ni, D. Wang, M. Fu, and T. Hong, "Berberine suppresses mast cell-mediated allergic responses via regulating FceRI-mediated and MAPK signaling," International Immunopharmacology, vol. 71, pp. 1-6, 2019.

[32] T. T. Bui, C. H. Piao, E. Hyeon et al., "Preventive effect of Bupleurum chinense on nasal inflammation via suppressing $\mathrm{T}$ helper type 2, eosinophil and mast cell activation," The American Journal of Chinese Medicine, vol. 47, no. 2, pp. 405-421, 2019.

[33] M. Krystel-Whittemore, K. N. Dileepan, and J. G. Wood, "Mast cell: a multi-functional master cell," Frontiers Immunology, vol. 6, p. 620, 2016.

[34] F. Rousset, J. Robert, M. Andary et al., "Shifts in interleukin-4 and interferon- $\gamma$ production by $T$ cells of patients with elevated serum IgE levels and the modulatory effects of these lymphokines on spontaneous IgE synthesis," Journal of Allergy and Clinical Immunology, vol. 87, no. 1, pp. 58-69, 1991.

[35] M. Klliomaki, A. Ouwehand, H. Arvilommi, P. Kero, and E. Isolauri, "Transforming growth factor beta in the breastmilk: a potential regulator of atopic disease at an early age," Journal of Allergy and Clinical Immunology, vol. 104, no. 6, pp. 1251-1257, 1999.

[36] K. Laiho, U. Hoppu, A. C. Ouwehand, S. Salminen, and E. Isolauri, "Probiotics: on-going research on atopic individuals," British Journal of Nutrition, vol. 88, no. S1, pp. S19-S27, 2002.
[37] M. Kotani, M. Matsumoto, A. Fujita et al., "Persimmon leaf extract and astragalin inhibit development of dermatitis and IgE elevation in NC/Nga mice," Journal of Allergy and Clinical Immunology, vol. 106, no. 1, pp. 159-166, 2000.

[38] Y.-Y. Sung, S.-H. Kim, H. J. Yuk et al., "Siraitia grosvenorii residual extract attenuates ovalbumin-induced lung inflammation by down-regulating IL-4, IL-5, IL-13, IL-17, and MUC5AC expression in mice," Phytomedicine, vol. 61, Article ID 152835, 2019.

[39] Y. Fan, C. H. Piao, E. Hyeon et al., "Gallic acid alleviates nasal inflammation via activation of Th1 and inhibition of Th2 and Th17 in a mouse model of allergic rhinitis," International Immunopharmacology, vol. 70, pp. 512-519, 2019. 